\title{
Internet-Based Supportive Interventions for Family Caregivers of People With Dementia: Systematic Review and Meta-Analysis
}

\author{
Minmin Leng ${ }^{1,2^{*}}$, MD; Yajie Zhao ${ }^{1,2^{*}}$, MA; Hongmei Xiao ${ }^{1,2}, \mathrm{MA}$; $\mathrm{Li}^{1,2}, \mathrm{MA}$; Zhiwen Wang ${ }^{1,2}, \mathrm{PhD}^{2}$ \\ ${ }^{1}$ School of Nursing, Peking University, Beijing, China \\ ${ }^{2}$ Peking University Health Science Centre for Evidence-Based Nursing: A Joanna Briggs Institute Affiliated Group, Beijing, China \\ *these authors contributed equally
}

\section{Corresponding Author:}

Zhiwen Wang, PhD

School of Nursing

Peking University

38 Xueyuan Road, Haidian District

Beijing, 100191

China

Phone: 8615901566817

Email: wzwjing@sina.com

\section{Abstract}

Background: Caring for people with dementia is perceived as one of the most stressful and difficult forms of caring. Family caregivers always experience high levels of psychological burden and physical strain, so effective and practical support is essential. Internet-based supportive interventions can provide convenient and efficient support and education to potentially reduce the physical and psychological burden associated with providing care.

Objective: This review aimed to (1) assess the efficacy of internet-based supportive interventions in ameliorating health outcomes for family caregivers of people with dementia, and (2) evaluate the potential effects of internet-based supportive intervention access by caregivers on their care recipients.

Methods: An electronic literature search of the PubMed, EMBASE, Web of Science, CINAHL, Cochrane Library, and PsycINFO databases was conducted up to January 2020. Two reviewers (ML and YZ) worked independently to identify randomized controlled trials (RCTs) that met the inclusion criteria and independently extracted data. The quality of the included RCTs was evaluated using the approach recommended by the Cochrane Handbook for Systematic Reviews of Interventions. Standardized mean differences (SMDs) with 95\% CIs were applied to calculate the pooled effect sizes.

Results: In total, 17 RCTs met the eligibility criteria and were included in this systematic review. The meta-analysis showed that internet-based supportive interventions significantly ameliorated depressive symptoms $(\mathrm{SMD}=-0.21 ; 95 \% \mathrm{CI}-0.31$ to -0.10 ; $P<.001$ ), perceived stress (SMD $=-0.40 ; 95 \% \mathrm{CI}-0.55$ to $-0.24 ; P<.001)$, anxiety $(\mathrm{SMD}=-0.33 ; 95 \% \mathrm{CI}-0.51$ to $-0.16 ; P<.001)$, and self-efficacy $(\mathrm{SMD}=0.19 ; 95 \% \mathrm{CI} 0.05-0.33 ; P=.007)$ in dementia caregivers. No significant improvements were found in caregiver burden, coping competence, caregiver reactions to behavioral symptoms, or quality of life. Six studies assessed the unintended effects of internet-based supportive intervention access by caregivers on their care recipients. The results showed that internet-based supportive interventions had potential benefits on the quality of life and neuropsychiatric symptoms in care recipients.

Conclusions: Internet-based supportive interventions are generally effective at ameliorating depressive symptoms, perceived stress, anxiety, and self-efficacy in dementia caregivers and have potential benefits on care recipients. Future studies are encouraged to adopt personalized internet-based supportive interventions to improve the health of family caregivers and their care recipients.

Trial Registration: PROSPERO CRD42020162434; https://www.crd.york.ac.uk/prospero/display_record.php?RecordID=162434

(J Med Internet Res 2020;22(9):e19468) doi: 10.2196/19468

\section{KEYWORDS}

family caregivers; dementia; supportive interventions; internet; systematic review 


\section{Introduction}

According to World Alzheimer Report 2018 [1], dementia affects almost 50 million people globally, with a new case of dementia occurring around the world every 3 seconds; this number is expected to increase to an alarming 152 million by 2050. Most people with dementia live at home and are cared for primarily by their spouse or adult children, the informal caregivers [2]. Caring for people with dementia is perceived as one of the most stressful experiences, as family caregivers may face long-term problems of managing activities of daily living $[3,4]$, behavioral and psychological symptoms [5,6], and organizing care and providing emotional support [7,8]. However, due to a lack of supportive resources and knowledge of dementia, family caregivers have low confidence in managing caregiving [9] and do not know what to do when their relatives have dementia-related behavioral problems, need emotional support, and require the coordination of dementia care [10]. In addition, improper care behavior can also induce care recipients to develop various behavioral and psychological problems. As a result, dementia family caregivers always experience higher levels of psychological burden, physical strain, and ineffective coping than caregivers of older adults with physical impairments $[11,12]$.

With the given physical and psychological impacts on family caregiver well-being, effective and practical support for family caregivers is essential. The Alzheimer's Disease International points out that help and support for caregivers should be a fundamental lynchpin of any national dementia plan [13]. Most currently available interventions to support family caregivers of people with dementia are "face-to-face" interventions [14-16], but the uptake of such interventions is poor. It is estimated that only a small percentage of family caregivers access caregiver support services, with the difficulty of leaving the care recipient and stigma being the main obstacles to uptake [17,18]. In addition, the continued increase in the number of people with dementia has led to concerns about whether the current labor force can cope with such an increased future caring demand [19].

Internet-based supportive interventions could be an efficient alternative to close the support gap to provide education and support for family caregivers, especially for those finding it difficult to leave their care recipient or requiring flexibility due to caring responsibilities. The benefits of interventions provided via the internet are that they are relatively low cost and more convenient because they enable family caregivers to learn at anytime and anywhere [20,21]. The growing number of randomized controlled trials (RCTs) in the field of internet-based support reflects the increasing demand for strategies that can complement existing services and better support family caregivers providing care to people with dementia.

Recent systematic reviews have concluded that internet-based supportive interventions can improve health outcomes in family caregivers of people with chronic disease [22-24]. However, the findings regarding the effect of internet-based supportive interventions on the improvement of health outcomes in family caregivers of people with dementia have been inconsistent. For example, some RCTs have indicated that the level of caregiver burden [25,26], depressive symptoms [25,27], or coping competence $[25,28]$ was significantly ameliorated in the internet-based group compared with the control group. Conversely, some trials have shown that there were no significant differences detected in caregiver burden [29,30], depressive symptoms [29,31], or coping competence [26,30] between the internet-based and control groups.

Currently, there are several systematic reviews of internet-based supportive interventions for family caregivers of people with dementia. In a previous systematic review [32], the author included 14 empirical studies; the results indicated that computer-mediated interventions were potentially useful as a supportive intervention. Nonetheless, because the study design of the included studies was diverse and the data were insufficient, the authors only described the inconsistent results and did not conduct a meta-analysis. A recent meta-analysis [33] investigated the effects of internet-based interventions on mental health outcomes for home caregivers of people with dementia. However, the number of articles included in this meta-analysis was limited. In another recent systematic review [11] of internet-based interventions for family caregivers of people with dementia, the authors mainly aimed to identify the key components of existing internet-based interventions designed to support family caregivers of people with dementia and explore which components are most valued by family caregivers.

In summary, the effects of internet-based supportive interventions on family caregivers of people with dementia require further exploration. Furthermore, to the best of our knowledge, there has been no systematic review that has evaluated the potential effects of internet-based supportive intervention access by family caregivers on their care recipients. Thus, we performed this systematic review and meta-analysis to further clarify the effects of internet-based supportive interventions on dyads (caregivers + people with dementia). The primary objectives of this study were to assess the efficacy of internet-based supportive interventions in ameliorating health outcomes for family caregivers of people with dementia and examine whether specific types of internet-based supportive interventions had a beneficial impact on family caregivers' health outcomes. The secondary objective was to evaluate the potential effects of internet-based supportive intervention access by caregivers on their care recipients.

\section{Methods}

We conducted this systematic review and meta-analysis of RCTs by following the Preferred Reporting Items for Systematic Review and Meta-Analyses (PRISMA) guidelines [34]. The research protocol was registered in PROSPERO (registration number CRD42020162434).

\section{Literature Search Strategy}

An electronic literature search of the PubMed, EMBASE, Web of Science, CINAHL, Cochrane Library, and PsycINFO databases was conducted up to January 2020. Additional relevant studies were identified through the reference lists of the included 
studies and previous related systematic reviews. For each database, the search strategy was customised. The key search terms were a combination of medical subject heading terms (MeSH) and entry terms. The detailed information about the search strategies and search results of each database is available in Multimedia Appendix 1.

\section{Inclusion Criteria}

Studies were included in this review if they met the following criteria: (1) participants were family caregivers who were currently providing caregiving support to people with dementia, defined as a family member such as their spouse or adult children providing unpaid care; (2) the intervention was a digital one delivered via any internet-based modality, which could include either single-component interventions or multiple-component interventions to family caregivers; (3) comparison was usual care or minimal support control by using paper materials, telephone, or email, etc; (4) primary outcomes included outcome variables related to family caregivers of people with dementia (depressive symptoms, caregiver burden, coping competence, perceived stress, caregiver reaction to behavioral symptoms, anxiety, quality of life, and self-efficacy), and secondary outcomes included outcome variables related to people with dementia (care recipient' quality of life and neuropsychiatric symptoms); and (5) to achieve high levels of evidence, we included only RCTs.

\section{Study Selection and Data Extraction}

All of the searched records were imported into EndNote X9 to eliminate duplicate studies. Two reviewers (ML and YZ) worked independently to identify studies that met the inclusion criteria. To further evaluate the eligibility of potential studies, we obtained full-text articles and discussed any disagreements with the third reviewer (ZW). Data were extracted from the included studies by 2 independent reviewers (ML and YZ) using the standardized data extraction tool. From each included study, we extracted data including the author, publication year, country, sample size, participant' mean age, internet-based supportive intervention details (eg, methods, content, and duration), data collection time points, and outcome measurement tools. Any disagreements between the 2 independent reviewers were resolved by the third reviewer (ZW).

\section{Quality Appraisal}

The risk of bias in the included studies was assessed using the approach recommended by the Cochrane Handbook for
Systematic Reviews of Interventions [35]. The 7 recommended items included random sequence generation, allocation concealment, blinding of participants and personnel, blinding of outcome assessors, incomplete outcome data, selective reporting, and other bias. All included studies were independently evaluated, and the risk of bias for each item was categorized as "low risk," "unclear," or "high risk." Disagreements between the 2 reviewers were resolved by the third reviewer $(\mathrm{ZW})$.

\section{Data Analysis}

Standardized mean differences (SMDs) with 95\% CIs were used when studies used different outcome scales, and mean differences (MDs) with 95\% CIs were applied when studies used the same outcome scales. The level of heterogeneity was evaluated by the $I^{2}$ method, and a value of $I^{2}>50 \%$ was regarded as significant heterogeneity [36]. The fixed-effects model was used to calculate the pooled effect size if the data were not significantly heterogeneous. Otherwise, the random-effects model was used. A sensitivity analysis was performed by excluding one study at a time to confirm the consistency of the findings. Publication bias was evaluated by visual inspection of funnel plot. RevMan 5.3 provided by the Cochrane Collaboration was used for all statistical calculations, and a $P$ value $<.05$ was considered statistically significant.

In the systematic review, intervention formats were divided into personalized and nonpersonalized formats. Subgroup analyses were performed to explore which internet-based supportive intervention format was most beneficial for family caregivers of people with dementia.

\section{Results}

\section{Study Selection}

A total of 9110 records were identified from the electronic databases in the final search, with an additional 7 records identified through other sources. After removal of duplicates and obviously irrelevant records, we retrieved 182 full-text articles to further evaluate their eligibility. In total, 165 articles were excluded because they did not meet the inclusion criteria. Ultimately, a total of 17 studies [25-31,37-46] involving 2202 family caregivers of people with dementia were included in this systematic review. The detailed screening process is illustrated in Figure 1. 
Figure 1. Flow diagram for search and selection of the included studies.

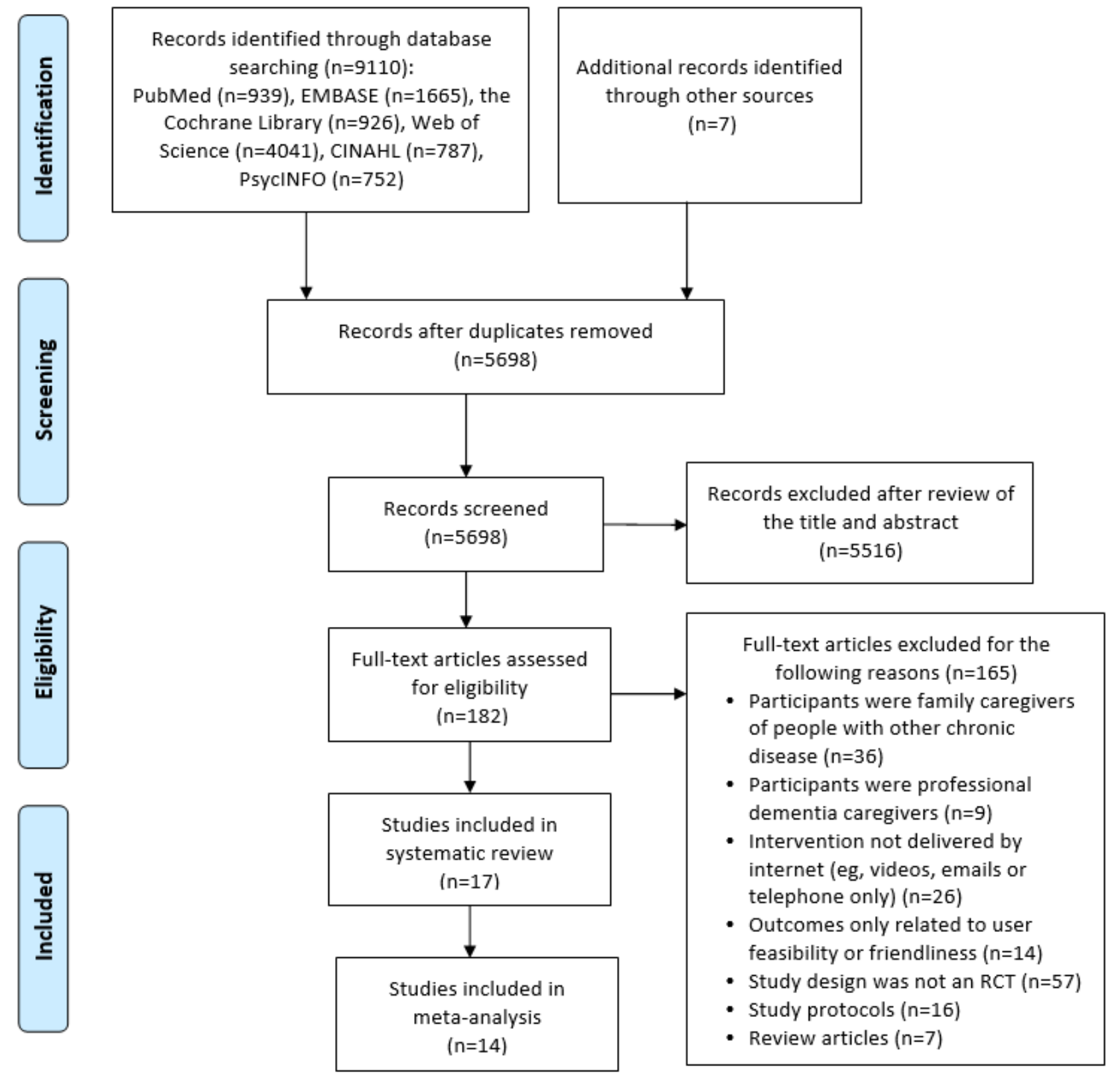

\section{Study Characteristics}

The number of participants in each study ranged from 25 to 547. The intervention duration ranged from 4 weeks to 12 months. Eight studies were performed in the United States $[25,26,31,38,41,42,44,46], 3$ studies were performed in Netherlands [28,37,40], 2 studies were performed in France $[29,43]$, and 1 study each was conducted in Canada [39], Germany [30], Spain [27], and the UK [45]. All of the included studies reported clear inclusion and exclusion criteria for their participants. In 9 studies, the forms of internet-based support interventions were personalized [25,27,28,40-42,44-46] whereas in the other 8 studies [26,29-31,37-39,43], they were nonpersonalized. The nature of the treatment of control group participants differed from one study to another. The control groups in 10 studies [25,27-30,40,42-45] were exposed to the same conditions as the corresponding intervention groups, except for the implementation of internet-based support intervention in the latter. However, in some studies, the control group received e-bulletins [37], booklet [39], or book [26] while the intervention group received internet-based support intervention. Similarly, Brennan et al [38] provided placebo training experience identifying local services and resources for the comparison group. In the studies of Hicken et al [41] and Williams et al [46], caregivers in the control group received telephone-support attention. Kajiyama et al [31] provided a website containing the similar navigational features to caregivers in the control condition, but they did not provide any of the information or skills training content presented in the intervention group. All 17 included studies evaluated the effect of internet-based supportive interventions in ameliorating health outcomes for family caregivers of people with dementia, and 6 studies [28,29,42-45] also reported potential effects of internet-based supportive intervention access by caregivers on their care recipients. The main characteristics of the included studies are presented in Multimedia Appendix 2. 


\section{Risk of Bias Assessment}

In general, the RCTs included in this systematic review showed an acceptable risk of bias. Most of the included studies reported randomization, but some trials did not describe the allocation concealment details, which could cause potential selection bias. However, only 2 studies [37,39] were judged as having a low risk of performance bias because it was difficult to blind the participants in psychosocial intervention trials. Approximately half of the studies blinded outcome assessors; therefore, their risk of detection bias was categorized as low. The risk of attrition bias was judged as unclear in only 1 study [41], and there was no evidence of selective reporting bias in any of the included studies. The risk of other bias was categorized as high in 4 studies because of the baseline differences $[29,45]$ and small sample sizes $[26,30]$. The risk of bias assessment of each included study is shown in Figure 2.

Figure 2. Risk of bias summary: review of the authors' judgments about each risk of bias item for each included study.

\begin{tabular}{|c|c|c|c|c|c|c|c|}
\hline & 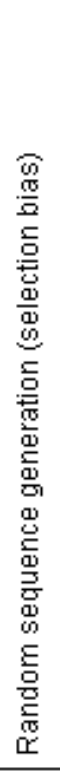 & 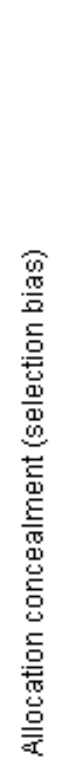 & 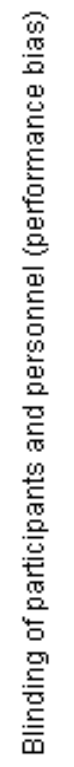 & 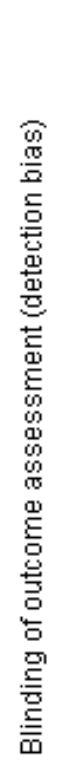 & 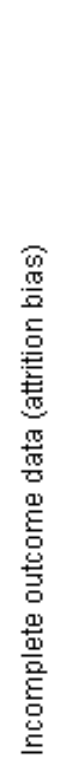 & 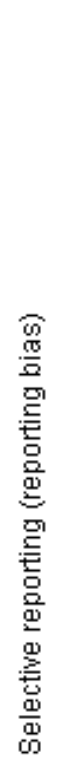 & 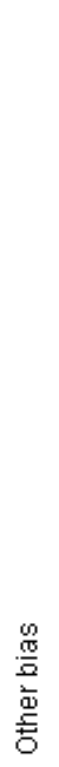 \\
\hline Beauchamp et al. 2005 [25] & $?$ & $?$ & $?$ & + & $\odot$ & $\oplus$ & $\odot$ \\
\hline Blom et al. 2015 [37] & $\odot$ & $\odot$ & $\odot$ & $\odot$ & $\odot$ & 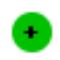 & $\odot$ \\
\hline Brennan et al. 1995 [38] & $?$ & $?$ & $?$ & $?$ & $\odot$ & $\oplus$ & $\oplus$ \\
\hline Cristancho-Lacroix et al. 2015 [29] & + & $?$ & $?$ & 0 & + & + & $\theta$ \\
\hline Duggleby et al., 2018 [39] & $\odot$ & $\odot$ & $\odot$ & $\odot$ & $\odot$ & 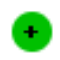 & $\odot$ \\
\hline Gustafson et al. 2019 [26] & $?$ & $?$ & $?$ & $?$ & + & + & O \\
\hline Hattink et al. 2015 [40] & $\odot$ & $?$ & $?$ & $\odot$ & 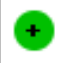 & 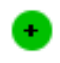 & $\odot$ \\
\hline Hicken et al., 2017 [41] & $?$ & $?$ & $?$ & 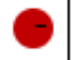 & $?$ & + & $\odot$ \\
\hline Kajiyama et al. 2013 [31] & $?$ & $?$ & $?$ & + & + & + & $\odot$ \\
\hline Kales et al., 2018 [42] & $\odot$ & + & $?$ & $?$ & + & + & 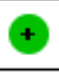 \\
\hline Meichsner et al. 2019 [30] & $\odot$ & $?$ & $?$ & $?$ & $\odot$ & 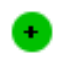 & ○ \\
\hline Metcalfe et al., 2019 [43] & $\odot$ & + & $?$ & $?$ & + & + & $\odot$ \\
\hline Núñez-Naveira et al. 2016 [27] & $\odot$ & $?$ & $?$ & $\odot$ & + & + & 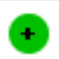 \\
\hline Possin et al. 2019 [44] & $\odot$ & $?$ & $\theta$ & + & $\odot$ & $\odot$ & $\odot$ \\
\hline Torkamani et al. 2014 [45] & $?$ & $?$ & $?$ & $?$ & + & + & \\
\hline Van Mierlo et al., 2015 [28] & 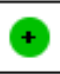 & + & $?$ & + & $\odot$ & + & + \\
\hline Williams et al., 2019 [46] & $\odot$ & $?$ & $?$ & $?$ & $\odot$ & $\oplus$ & $\odot$ \\
\hline
\end{tabular}


Meta-Analysis Results of Interventions Among Family Caregivers

\section{Depressive Symptoms}

A total of 11 studies assessed the effects of internet-based supportive interventions on depressive symptoms using the Centre for Epidemiologic Studies Depression Scale $[25,27,30,31,37,38,42,46]$, Patient Health Questionnaire [26,44], and Beck Depression Inventory-II Scale [29]. Because of the different assessment tools, we used the SMD to represent the pooled effect size. The meta-analysis showed that caregivers in the internet-based supportive intervention group exhibited a significant amelioration of depressive symptoms compared with controls (n=1524; $\mathrm{SMD}=-0.21 ; 95 \% \mathrm{CI}-0.31$ to $-0.10 ; P<.001$; $I^{2}=0 \%$, fixed-effects model; Figure 3).

Figure 3. The effect of internet-based supportive interventions on depressive symptoms.

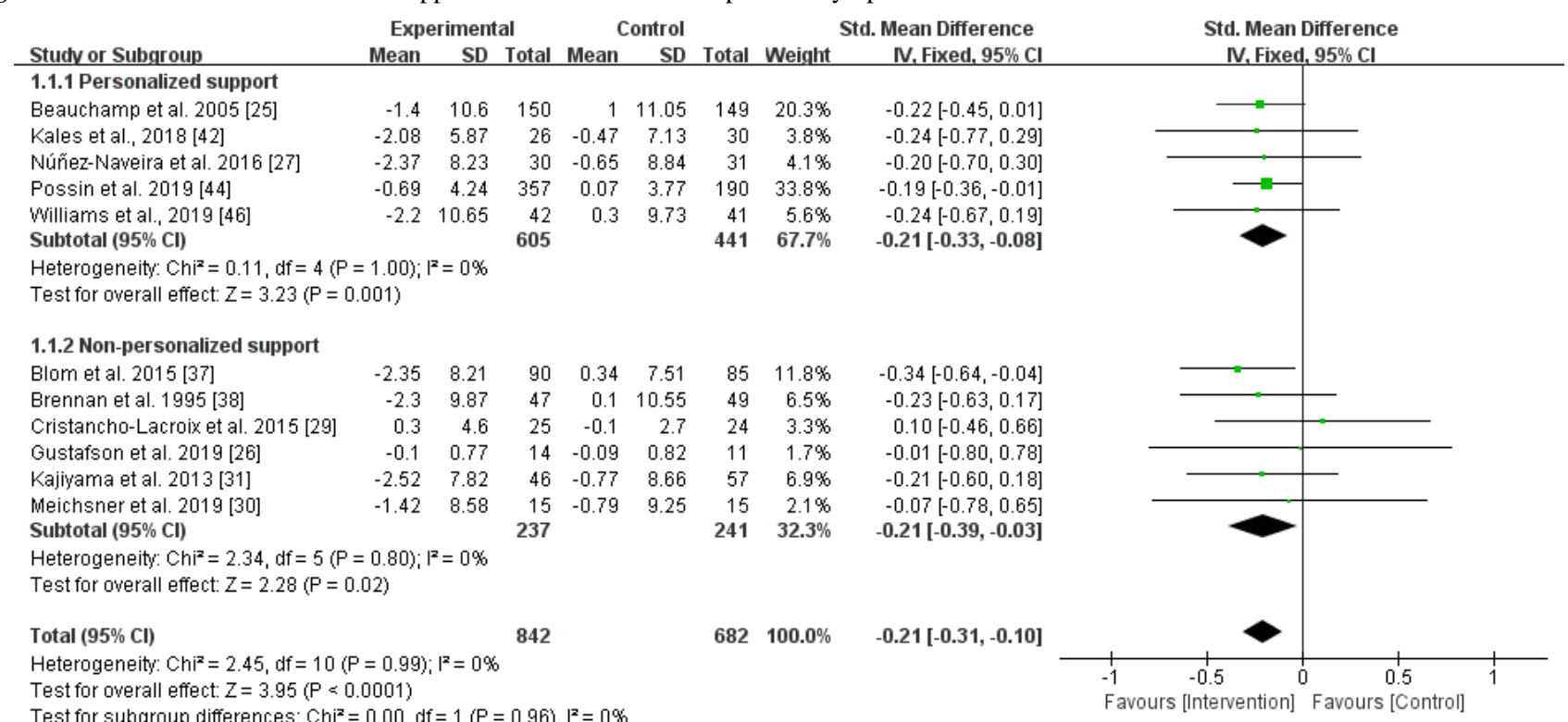

For the subgroup analysis, 5 studies reported detailed data on personalized format interventions [25,27,42,44,46], while 6 studies reported detailed data on nonpersonalized format interventions [26,29-31,37,38]. In the personalized format subgroup, the results showed that the caregivers in the intervention group had a significant reduction in SMD scores for depressive symptoms compared with the caregivers in the control group $(\mathrm{n}=1046 ; \mathrm{SMD}=-0.21 ; 95 \% \mathrm{CI}-0.33$ to -0.08 ; $P=.001 ; I^{2}=0 \%$, fixed-effects model; Figure 3$)$. In the nonpersonalized format subgroup, a significant reduction in SMD scores for depressive symptoms was also observed $(n=478$; $\mathrm{SMD}=-0.21 ; 95 \%$ CI -0.39 to $-0.03 ; \quad P=.02 ; \quad I^{2}=0 \%$, fixed-effects model; Figure 3).

\section{Caregiver Burden}

A total of 10 studies evaluated the effects of internet-based supportive interventions on caregiver burden measured by the Zarit Burden Interview [29,42,44-46], the Caregiver Strain Instrument [25], the Caregiver Load scale [26], the Burden Scale for Family Caregivers [43], the Burden Visual Analog scale [30], and 1 question [40]. Because of the different measuring tools, we applied the SMD to represent the pooled effect size. The meta-analysis showed that the overall combined effect of the internet-based supportive intervention on caregiver burden was not statistically significant $(\mathrm{n}=1252 ; \mathrm{SMD}=-0.10 ; 95 \% \mathrm{CI}$ -0.21 to $0.02 ; P=.09 ; I^{2}=0 \%$; fixed-effects model; Figure 4 ).

In the personalized format subgroup, the results from 6 studies $[25,40,42,44-46]$ showed that internet-based supportive interventions improved the burden status of caregivers with an SMD score of -0.11 , but the difference was not statistically significant $(\mathrm{n}=1088 ; \mathrm{SMD}=-0.11 ; 95 \% \mathrm{CI}-0.23$ to $0.02 ; P=.09$; $I^{2}=0 \%$; fixed-effects model; Figure 4 ). In the nonpersonalized format subgroup, the results from 4 studies [26,29,30,43] showed that internet-based supportive interventions improved the burden status of caregivers with an SMD score of -0.04 , and this difference was also not statistically significant $(n=164$; $\mathrm{SMD}=-0.04 ; 95 \% \mathrm{CI}-0.34$ to $0.27 ; P=.82 ; I^{2}=0 \%$; fixed-effects model; Figure 4). 
Figure 4. The effect of internet-based supportive interventions on caregiver burden.

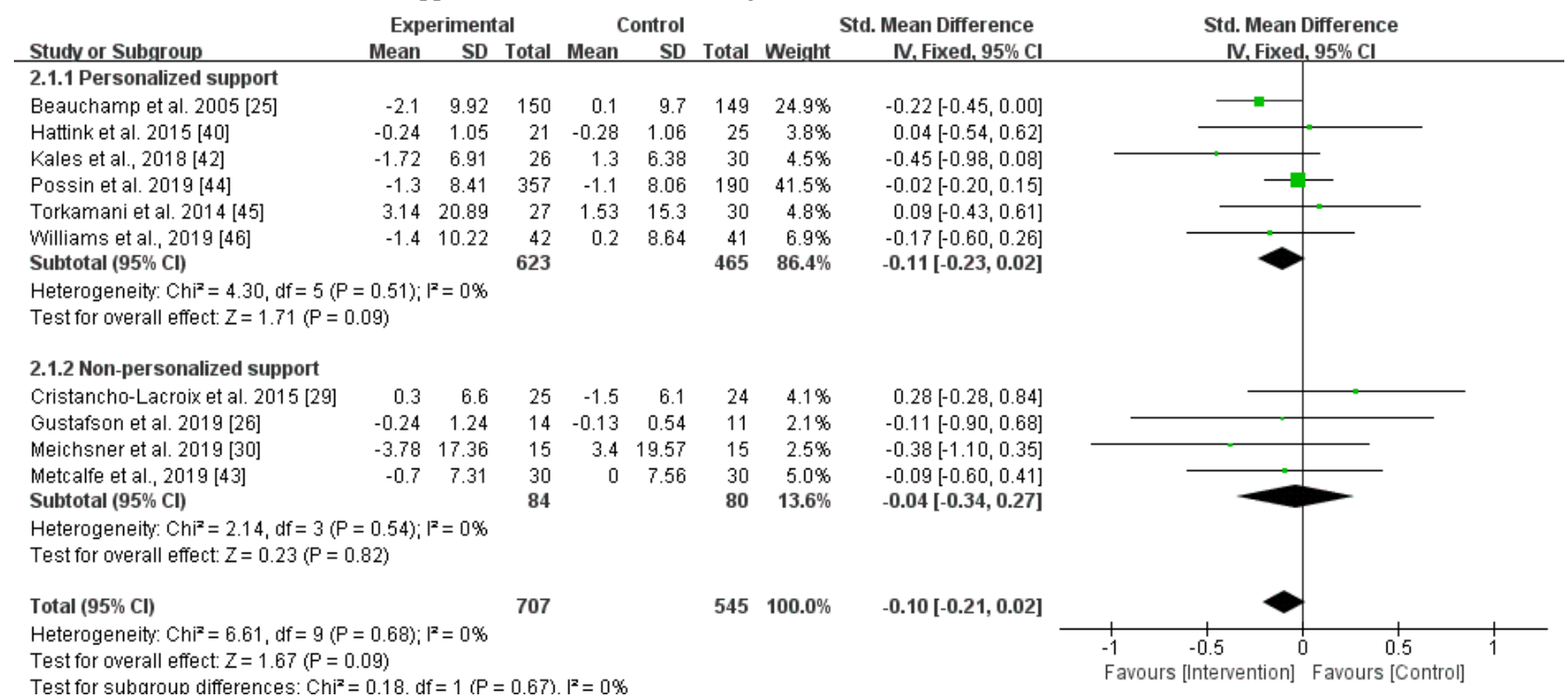

\section{Perceived Distress/Stress}

A total of 7 studies reported the effects of internet-based supportive interventions on distress/stress measured by the Perceived Stress Scale [29,31,43], Neuropsychiatric Inventory subscale [42,45], Interpersonal Reactivity Index subscale [40], and 2 questions [25]. A significant improvement in distress/stress after internet-based supportive intervention was observed compared with the control condition $(\mathrm{n}=663$; $\mathrm{SMD}=-0.40 ; 95 \%$ CI -0.55 to $-0.24 ; \quad P<.001 ; I^{2}=4 \%$, fixed-effects model; Figure 5).

Figure 5. The effect of internet-based supportive interventions on perceived distress/stress.

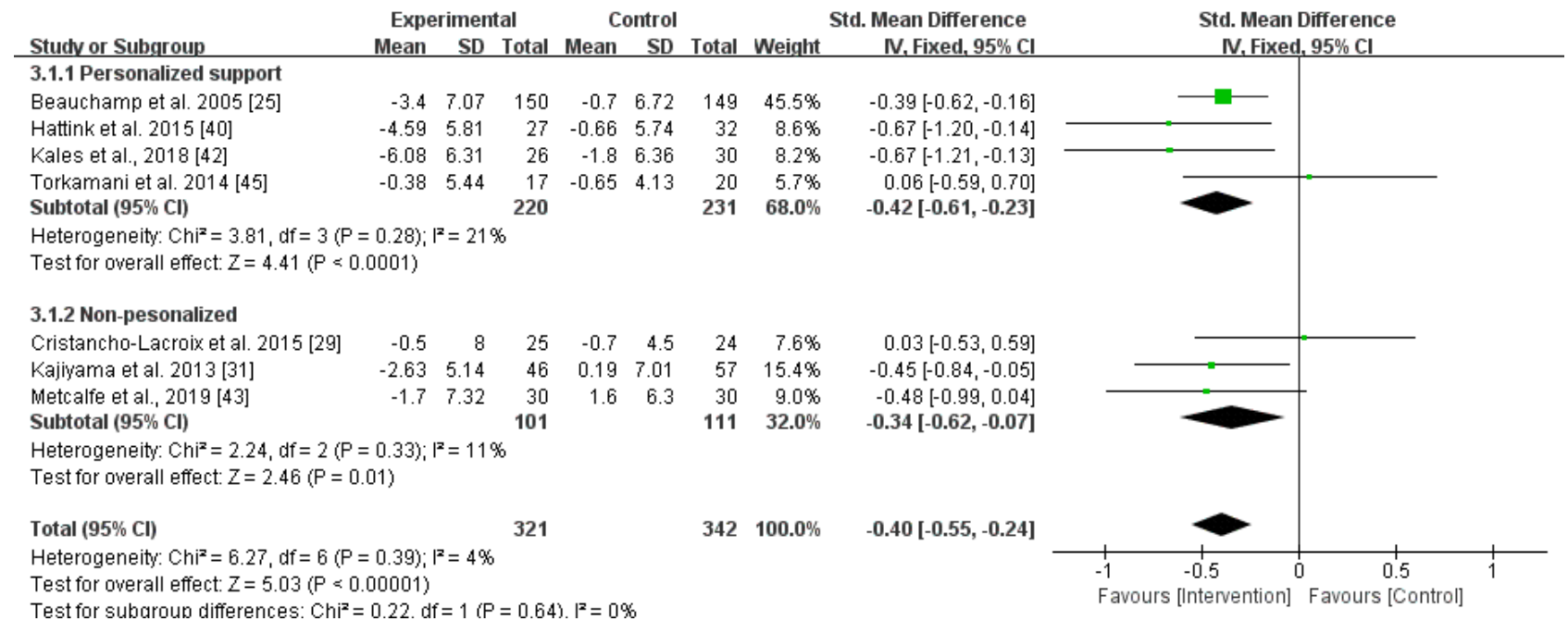

As much as 4 studies reported detailed data on personalized format interventions [25,40,42,45], while 3 studies reported detailed data on nonpersonalized format interventions $[29,31,43]$. In the personalized format subgroup, the results showed that the internet-based interventions had a significant beneficial effect on distress/stress $(\mathrm{n}=451 ; \mathrm{SMD}=-0.42 ; 95 \%$ CI -0.61 to $-0.23 ; P<.001 ; I^{2}=21 \%$, fixed-effects model; Figure $5)$. In the nonpersonalized format subgroup, a significant beneficial effect on distress/stress was also observed $(n=212$; $\mathrm{SMD}=-0.34 ; 95 \%$ CI -0.62 to $-0.07 ; \quad P=.01 ; I^{2}=11 \%$, fixed-effects model; Figure 5).

\section{Coping Competence}

A total of 7 studies used coping competence as an outcome variable, using the Short Sense of Competence Questionnaire [40,46], Caregiver Competence Scale [27], Revised Ways of Coping [25], Visual Analog Scale of coping [29], Caregiver Appraisal Scale [26], and Caregiver Grief Scale [30] to assess coping competence. The meta-analysis results showed that internet-based supportive interventions had no significant effect on coping competence $(\mathrm{n}=593 ; \mathrm{SMD}=0.11 ; 95 \% \mathrm{CI}-0.05$ to 0.27; $P=.19 ; I^{2}=0 \%$; fixed-effects model; Figure 6). 
Figure 6. The effect of internet-based supportive interventions on coping competence.

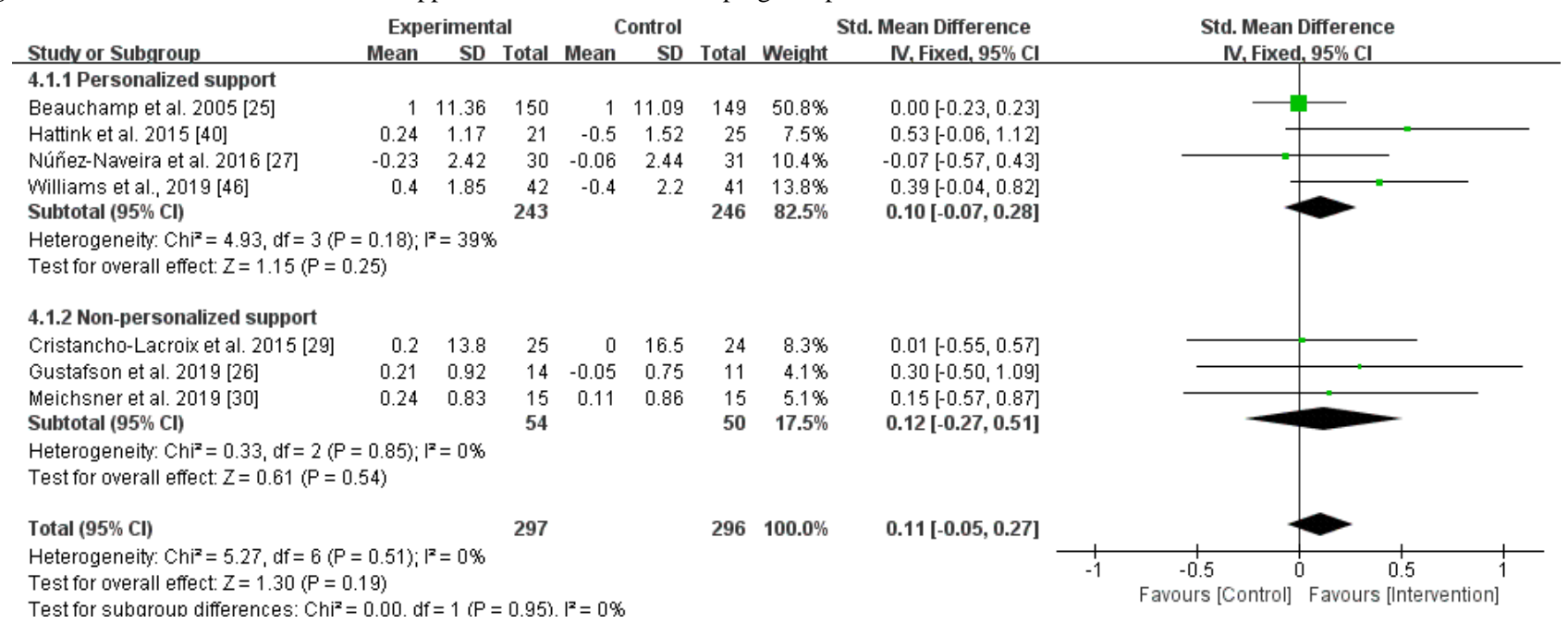

In the personalized format subgroup, the results from 4 studies $[25,27,40,46]$ showed that the effect of the internet-based supportive interventions on coping competence was not statistically significant $(\mathrm{n}=489 ; \mathrm{SMD}=0.10 ; 95 \% \mathrm{CI}-0.07$ to $0.28 ; P=.25 ; I^{2}=39 \%$; fixed-effects model; Figure 6 ). In the nonpersonalized format subgroup, the results from 3 studies $[26,29,30]$ showed a similar effect $(\mathrm{n}=108 ; \mathrm{SMD}=0.12 ; 95 \%$ CI -0.27 to $0.51 ; P=.54 ; I^{2}=0 \%$; fixed-effects model; Figure 6 ).

\section{Caregiver Reactions to Behavioral Symptoms}

The effects of internet-based supportive interventions on caregiver reactions to behavioral symptoms of people with dementia were evaluated in 4 studies using the Revised Memory and Behavior Problems Checklist $[29,31,43,46]$. Because the measuring tool was the same, we applied the MD to represent the pooled effect size. The meta-analysis results showed that internet-based supportive interventions had no significant effect on caregiver reaction to behavioral symptoms $(\mathrm{n}=294$; $\mathrm{MD}=-0.11 ; 95 \% \mathrm{CI}-0.27$ to $0.06 ; P=.20 ; I^{2}=42 \%$; fixed-effects model; Figure 7).

Figure 7. The effect of internet-based supportive interventions on caregiver reaction to behavioral symptoms.

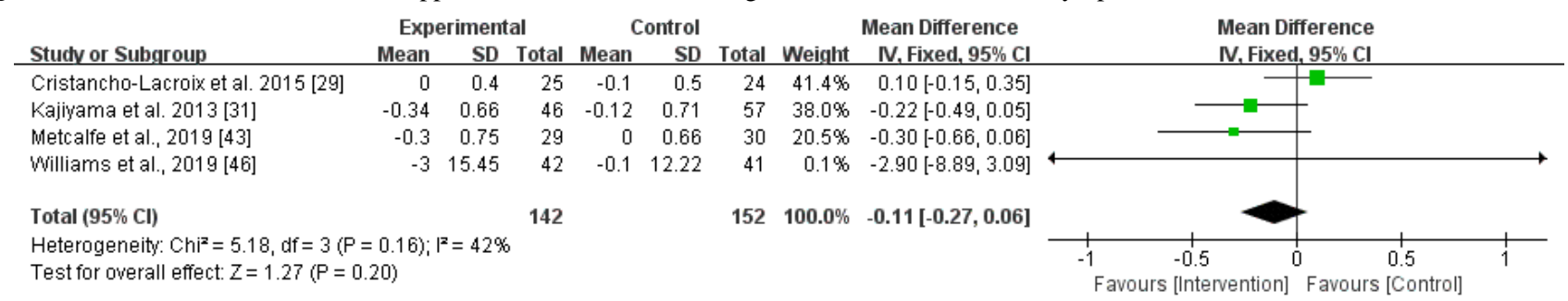

\section{Anxiety}

Three studies used anxiety as an outcome variable, using the State-Trait Anxiety Inventory [25], Hospital Anxiety and Depression subscale [37], and Generalized Anxiety Disorder

Figure 8. The effect of internet-based supportive interventions on anxiety.

\begin{tabular}{|c|c|c|c|c|c|c|c|}
\hline \multirow[b]{2}{*}{ Studv or Subgroup } & \multicolumn{3}{|c|}{ Experimental } & \multicolumn{2}{|c|}{ Control } & \multirow[b]{2}{*}{ Total } & \multirow[b]{2}{*}{ Weight } \\
\hline & Mean & SD & Total & Mean & SD & & \\
\hline Beauchamp et al. 2005 [25] & -0.9 & 5.7 & 150 & 0.9 & 6.4 & 149 & $60.2 \%$ \\
\hline Blom et al. 2015 [37] & -1.69 & 3.26 & 90 & -0.47 & 3.41 & 85 & $35.0 \%$ \\
\hline Gustafson et al. 2019 [26] & -0.28 & 0.18 & 14 & 0.05 & 0.81 & 11 & $4.8 \%$ \\
\hline Total $(95 \% \mathrm{Cl})$ & & & 254 & & & 245 & $100.0 \%$ \\
\hline
\end{tabular}

\section{Quality of Life}

Three studies reported the effects of internet-based supportive interventions on quality of life of dementia caregivers measured by the Perceived Quality of Life [31], Quality of Life Scale [45], and 2 distinct questions [40]. The meta-analysis showed
Scale [26] to assess changes in caregiver anxiety status. The results showed that compared with the control caregivers, the caregivers in the intervention group experienced significant amelioration of anxiety $(\mathrm{n}=499 ; \mathrm{SMD}=-0.33 ; 95 \% \mathrm{CI}-0.51$ to $-0.16 ; P<.001 ; I^{2}=0 \%$; fixed-effects model; Figure 8).

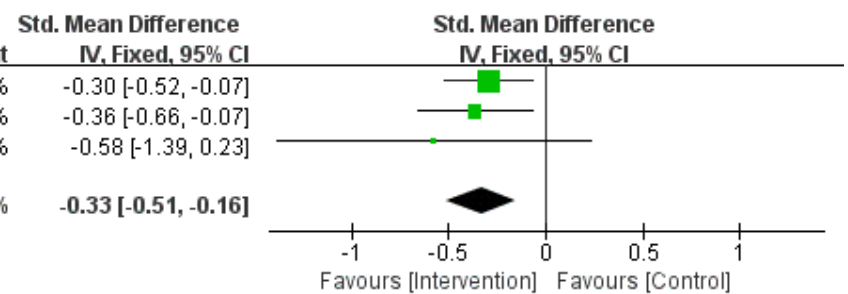

that the effect of the internet-based supportive intervention on quality of life was not statistically significant $(n=187$; $\mathrm{SMD}=0.15 ; 95 \% \mathrm{CI}-0.14$ to $0.44 ; P=.31 ; I^{2}=26 \%$; fixed-effects model; Multimedia Appendix 3). 


\section{Self-Efficacy}

In 2 studies, self-efficacy was used as the outcome variable, and the Caregiver Self-Efficacy Scale [44] and 6 self-efficacy questions regarding areas of caregiving [25] were used to measure self-efficacy. The results from the 2 studies showed that the internet-based supportive interventions had a significant beneficial effect on self-efficacy $(n=846 ; \mathrm{SMD}=0.19 ; 95 \% \mathrm{CI}$ 0.05 to $0.33 ; P=.007 ; I^{2}=0 \%$; fixed-effect models; Multimedia Appendix 4).

\section{Description of Studies Not Suitable for Meta-Analysis}

Three RCTs $[28,39,41]$ were not included in the meta-analysis due to the limitation of data types. Instead, the results of these studies are described and summarized in the following narrative review. Van Mierlo et al [28] found that an internet-based supportive intervention significantly improved the sense of competence of caregivers after 12 months $(P=.03)$. However, there were no significant differences in emotional stress between the intervention and control groups. Hicken et al [41] evaluated the effects of an internet-based supportive intervention for 4-6 months in family caregivers of veterans with dementia. There were no significant differences in the changes in caregiver burden or depressive symptoms between the groups from baseline to the end of the intervention. The important findings in this study were that the effects partly changed when the analyses were stratified by rurality. For urban caregivers, the burden score remained stable in the control group but decreased in the internet group $(P=.014)$. For rural caregivers, there were no significant differences between the groups. Duggleby et al [39] assessed the effects of 3 months of an internet-based supportive intervention on self-efficacy among caregivers of older adults with Alzheimer's disease and multiple chronic conditions. Although no significant group differences were observed in outcome measures, the caregivers in the intervention group indicated, when asked in interviews, that the internet-based supportive intervention helped them with their transitions.

\section{Potential Effects on Care Recipients}

Six studies [28,29,42-45] evaluated the potential effects of internet-based supportive intervention access by caregivers on their care recipients. Van Mierlo et al [28] examined the effects of DEMentia Digital Interactive Social Chart (DEM-DISC) access by caregivers on their care recipients. The results showed no significant differences between the intervention and control groups on the quality of life and neuropsychiatric symptoms of people with dementia as reported by family caregivers at 12 months. Two other studies [29,42] indicated similar results; there were no significant differences in behavioral frequency, severity, or overall neuropsychiatric symptoms between the intervention and control groups. Conversely, a recent RCT [44] showed that the quality of life of care recipients significantly declined more in the usual care group than in the intervention group from baseline to 12 months $(P=.04)$. The rate of emergency department visits over a 12-month period significantly increased more in the usual care group than in the intervention group $(P=.04)$. However, there were no significant differences in rates of ambulance use $(P=.12)$ and hospital use $(P=.71)$ between the intervention and usual care groups. Another study [43] demonstrated that behavior problem frequency of care recipients significantly reduced more in the intervention group than in the control group from baseline to 6 weeks $(P=.04)$. In a previous study conducted by Torkamani et al [45], the comparison revealed a significant difference in neuropsychiatric symptoms, showing worse neuropsychiatric symptoms for care recipients in the intervention group than those in the control group at baseline. The group difference remained significant at 3 and 6 months. Therefore, it is difficult to distinguish whether the intervention is effective for the neuropsychiatric symptoms of care recipients. One positive finding was that the care recipients in the intervention group showed weight gain.

\section{Publication Bias and Sensitivity Analyses}

Visual inspection of the funnel plot did not reveal evidence of potential publication bias. The funnel plot is shown in Multimedia Appendix 5. We conducted the sensitivity analysis by removing all the studies included in this meta-analysis one by one, and confirmed that the findings were not significantly influenced by any single study.

\section{Discussion}

\section{Summary and Interpretation of Results}

A total of 17 studies of internet-based supportive interventions in family caregivers of people with dementia were included in our systematic review, and 14 studies were included in the meta-analyses. Unlike previous reviews in this field, this review not only explored the effects of internet-based interventions on family dementia caregivers but also focused on the effects on care recipients. The meta-analysis showed that internet-based supportive interventions significantly ameliorated depressive symptoms, perceived stress, anxiety, and self-efficacy in dementia caregivers. Both the personalized and nonpersonalized formats of internet-based supportive interventions significantly reduced depressive symptoms and perceived stress. However, current evidence failed to support the efficacy of internet-based supportive interventions on caregiver burden, coping competence, caregiver reactions to behavioral symptoms, or quality of life. The results based on 6 studies [28,29,42-45] showed that internet-based supportive interventions had potential benefits on the quality of life and neuropsychiatric symptoms in care recipients.

This systematic review showed that internet-based supportive interventions had significant beneficial effects on mental health, such as depressive symptoms, perceived distress/stress, and anxiety. Several systematic reviews have also recognized the potential for internet-based interventions in supporting family caregivers of people with dementia to maintain well-being and independence. Our results are comparable to a recently published meta-analysis by Zhao et al [33], who reported that web-based interventions had a positive effect on mental health in home caregivers of people with dementia. Another systematic review [11] identified a broad variety of internet-based interventions that focused on providing information; engaging with social care professionals; and providing peer support, psychological support, and decision support. Although the main focus of that review [11] was not on effectiveness, some internet-based 
multiple-component interventions showed promise in reducing depressive symptoms and anxiety in family caregivers. For these positive results, the possible reason is that internet-based supportive interventions can improve the dementia-related knowledge and care skills of family caregivers, thereby enhancing their confidence in managing caregiving and alleviating their negative emotions.

In this systematic review, subgroup analysis showed that both personalized and nonpersonalized formats of internet-based supportive interventions had significant beneficial effects on depressive symptoms and perceived stress. Compared with the effect size of the nonpersonalized format, the combined effect size of the personalized format was larger, which means that personalized format intervention was more beneficial for dementia family caregivers. Because the symptoms of people with dementia are diverse and the coping abilities of home caregivers are uneven, it is important to provide personalized interventions. The American Geriatrics Society points out that providing care that is respectful of and responsive to individual person needs, preferences, and values is one of the pillars of quality health care [47]. Recent guidelines [48-50] that offer best-practice advice on support and care for people with dementia and their families and caregivers stated that dementia care should be personalized to a person's interests, abilities, values, beliefs, personalities, life experiences, likes, and dislikes and should be based on the severity and characteristics of the symptoms. The personalized format of internet-based supportive interventions enables health-care professionals to understand and provide support for the unmet needs of individuals with dementia and their family caregivers. In Núñez-Naveira et al's study [27], at the start of the program, the participants needed to complete an interactive customization questionnaire with questions about the time availability for learning, energy, and preferences of the care provider and about the severity of dementia of the people cared for by the family caregiver. By completing the questionnaire, the information content provided to the family caregivers was personalized and adjusted to their personal situation. In Possin et al's study [44], care team members responded to family caregivers' immediate needs first, then screened for common problems and provided standardized education and tailored support according to the care plan protocols. In Williams et al's study [46], dementia care experts implemented personalized interventions by providing tailored feedback and guidance based on specific care encounters. The personalized interventions offered a user-friendly and promising method of individualizing professional consultation and guidance to maximize the intervention effects.

However, current evidence failed to support the efficacy of internet-based supportive interventions on caregiver burden, coping competence, caregiver reactions to behavioral symptoms, or quality of life. Studies have shown that caregiver outcomes, such as burden, have been shown to increase with time [51,52]. Although the internet-based supportive interventions did not significantly ameliorate those caregiver outcomes, they did lead to nonsignificant improvements in those caregiver outcomes. Internet-based supportive intervention is an emerging field, and the research in this field lacks consistency, such as inconsistent choice of theoretical models, inconsistent content in intervention courses, inconsistent doses of interventions, inconsistent conditions of control groups, and inconsistent measurement tools. These inconsistencies need to be taken seriously, so it is necessary to further explore the effects of these types of interventions.

In recent years, nonpharmacological interventions have been increasingly implemented to prevent and reduce challenging behavioral and psychological symptoms of dementia [53,54]. However, few of these interventions targeted people with dementia and their caregivers as dyads but rather people with dementia or caregivers alone [55]. In our systematic review, the evidence for potential effects on care recipients was limited, as only 5 of 17 RCTs provided effect data about care recipients. One study [44] showed that the quality of life and the rate of emergency department visits of care recipients increased significantly more in the intervention group than in the usual care group, whereas another study [28] indicated no significant differences between the intervention and control groups on the quality of life. Two studies [28,42] showed no significant differences between the intervention and control groups on the neuropsychiatric symptoms of people with dementia, whereas the other study [45] revealed unclear effects because of baseline differences. Another study [43] demonstrated that behavior problem frequency of care recipients was reduced significantly more in the intervention group than in the control group. Although the results were inconsistent across studies, they generally showed potential beneficial effects of internet-based supportive interventions on care recipients. Some outcome changes may not be statistically significant, but they are clinically significant for families who care for loved ones with dementia at home. In our opinion, internet-based supportive interventions can improve the caregiving skills of family caregivers, thereby meeting the complex care needs and providing better care for the people with dementia, and thus indirectly improve the health status of the people with dementia. Because of the limited evidence, further research is needed to explore the effects of internet-based supportive intervention access by caregivers on their care recipients.

\section{Implications for Clinical Practice and Future Research}

Our results demonstrate that internet-based supportive interventions have beneficial effects on family dementia caregivers and should be considered as a useful tool in clinical practice. The following issues need to be addressed when applying internet-based supportive interventions. First, the content of internet-based supportive interventions should be tailored according to user preferences, needs, personal situation, and dementia severity of the care recipients. It is better to provide online question-answering functionality on the internet platform so that dementia care experts can provide personalized feedback and guidance in a timely manner based on specific care encounters. Second, the ultimate goal of providing internet-based support services to family dementia caregivers is to improve the well-being of both dementia caregivers and people with dementia. Therefore, future studies should not only explore the effects of internet-based interventions on family dementia caregivers but also focus on their impact on care recipients. Third, privacy and security issues need to be highlighted. The details discussed by many users on the internet 
are emotional and personal topics. The overwhelming and vocal concerns about the internet have been data security and privacy [56]. The reasons for choosing and trusting a particular website are more focused on the way to access the website and the content of the website, including password-protected entry methods, personalized content, and unbiased information, rather than complex and busy layouts, irrelevant content, and corporate looks. Fourth, future research into internet-based supportive interventions for caregivers of people with dementia may benefit from a mixed-method approach. Qualitative components gathered from interviews with caregivers who have used internet-based supportive interventions provide a significant supplement to quantitative outcome measures. Qualitative approaches offer deeper insight into caregivers' experiences of using the interventions and taps into factors, such as feeling focused, supported, and less isolated, that are of great importance to caregivers. Finally, there is a need for further research in this field to promote cost-effective care and lower the threshold of seeking support around the world.

\section{Strengths and Limitations}

The strength of this systematic review was that we focused on the dyad of dementia, including family dementia caregivers and people with dementia, not only caregivers or only care recipients. In addition, only RCTs with rigorous study designs were included, which implies that the quality of evidence was relatively high. This systematic review also had some limitations. First, the included studies lacked consistency, the content and doses of interventions varied widely, and the tools for measuring outcome variables were diverse. Thus, the optimal intervention design for family dementia caregivers remains unclear. Second, only 6 studies evaluated the potential effects of internet-based supportive intervention access by caregivers on their care recipients. Therefore, the meta-analysis of the effects on care recipients was not performed, but only described and summarized in the narrative review. Third, some outcome variables, such as anxiety and self-efficacy, were not analyzed by subgroup due to the limited number of studies. Therefore, further research is needed to provide sufficient evidence for practice.

\section{Conclusions}

Internet-based supportive interventions are generally effective at ameliorating depressive symptoms, perceived stress, anxiety, and self-efficacy in family dementia caregivers and have potential benefits on care recipients, although negative results were found in some RCTs. Future studies are encouraged to adopt personalized internet-based supportive interventions to improve the health of family caregivers and their care recipients. Combining personalized information with the help of dementia care experts and the possibility of communicating with other family dementia caregivers can augment standard dementia care and improve the efficiency of resource utilization.

\section{Acknowledgments}

This work was supported by the Beijing Municipal Science \& Technology Commission (D171100008217007) and Chinese Nursing Association (ZHKY201915). The authors sincerely thank Drs Katherine Possin and Rachel Kiekhofer for providing the data from their study.

\section{Conflicts of Interest}

None declared.

\section{Multimedia Appendix 1}

Search Strategy.

[DOCX File, 26 KB-Multimedia Appendix 1]

\section{Multimedia Appendix 2}

Characteristics of the studies included in this systematic review.

[DOCX File , $41 \mathrm{~KB}$-Multimedia Appendix 2]

\section{Multimedia Appendix 3}

The effect of internet-based supportive interventions on quality of life.

[PNG File, 9 KB-Multimedia Appendix 3]

\section{Multimedia Appendix 4}

The effect of internet-based supportive interventions on self-efficacy.

[PNG File, 9 KB-Multimedia Appendix 4]

\section{Multimedia Appendix 5}

The funnel plot. 


\section{References}

1. Alzheimer's Disease International (ADI). World Alzheimer Report 2018: The State of the Art of Dementia Research: New Frontiers. 2018. URL: https://www.alz.co.uk/research/world-report-2018 [accessed 2020-04-16]

2. Wimo A. Establishing and funding long term care infrastructure. 2018 Jul Presented at: 33rd International Conference of Alzheimer's Disease International; 26-29 July, 2018; Chicago, IL p. 26-29.

3. Drummond N, McCleary L, Garcia L, McGilton K, Molnar F, Dalziel W, et al. Assessing Determinants of Perceived Quality in Transitions for People with Dementia: a Prospective Observational Study. Can Geriatr J 2019 Mar 04;22(1):13-22 [FREE Full text] [doi: $10.5770 /$ cgj.22.332] [Medline: $\underline{31501679}$ ]

4. Spigelmyer PC, Schreiber JB. A pilot study: Resistive behavior in the context of informal caregiver-assisted activities of daily living. Geriatr Nurs 2019 Jul;40(4):399-404. [doi: 10.1016/j.gerinurse.2019.01.005] [Medline: 30878279]

5. Huis In Het Veld JG, van Asch IFM, Willemse BM, Verkade P, Pot AM, Blom MM, et al. Process Evaluation of Nurse-Led Online Self-Management Support for Family Caregivers to Deal With Behavior Changes of a Relative With Dementia (Part 1): Mixed Methods Study. J Med Internet Res 2019 Oct 11;21(10):e13002 [FREE Full text] [doi: 10.2196/13002] [Medline: $\underline{31605517]}$

6. Baharudin AD, Din NC, Subramaniam P, Razali R. The associations between behavioral-psychological symptoms of dementia (BPSD) and coping strategy, burden of care and personality style among low-income caregivers of patients with dementia. BMC Public Health 2019 Jun 13;19(Suppl 4):447 [FREE Full text] [doi: 10.1186/s12889-019-6868-0] [Medline: $\underline{31196141]}$

7. Zwingmann I, Hoffmann W, Michalowsky B, Dreier-Wolfgramm A, Hertel J, Wucherer D, et al. Supporting family dementia caregivers: testing the efficacy of dementia care management on multifaceted caregivers' burden. Aging Ment Health 2018 Jul 20;22(7):889-896. [doi: 10.1080/13607863.2017.1399341] [Medline: 29156941]

8. Tatangelo G, McCabe M, Macleod A, You E. "I just don't focus on my needs." The unmet health needs of partner and offspring caregivers of people with dementia: A qualitative study. Int J Nurs Stud 2018 Jan;77:8-14. [doi:

10.1016/j.ijnurstu.2017.09.011] [Medline: 28982034]

9. Jennings LA, Reuben DB, Evertson LC, Serrano KS, Ercoli L, Grill J, et al. Unmet needs of caregivers of individuals referred to a dementia care program. J Am Geriatr Soc 2015 Feb 17;63(2):282-289 [FREE Full text] [doi: 10.1111/jgs.13251] [Medline: 25688604]

10. Peeters JM, Van Beek AP, Meerveld JH, Spreeuwenberg PM, Francke AL. Informal caregivers of persons with dementia, their use of and needs for specific professional support: a survey of the National Dementia Programme. BMC Nurs 2010 Jun 07;9(1):9 [FREE Full text] [doi: 10.1186/1472-6955-9-9] [Medline: 20529271]

11. Hopwood J, Walker N, McDonagh L, Rait G, Walters K, Iliffe S, et al. Internet-Based Interventions Aimed at Supporting Family Caregivers of People With Dementia: Systematic Review. J Med Internet Res 2018 Jun 12;20(6):e216 [FREE Full text] [doi: 10.2196/jmir.9548] [Medline: 29895512]

12. Joling KJ, O'Dwyer ST, Hertogh CM, van Hout HP. The occurrence and persistence of thoughts of suicide, self-harm and death in family caregivers of people with dementia: a longitudinal data analysis over 2 years. Int J Geriatr Psychiatry 2018 Feb 05;33(2):263-270 [FREE Full text] [doi: 10.1002/gps.4708] [Medline: 28379646]

13. Alzheimer's Disease International (ADI). World Alzheimer Report 2019: Attitudes to Dementia. 2019. URL: https://www. alz.co.uk/research/world-report-2019 [accessed 2020-04-16]

14. Sepe-Monti M, Vanacore N, Bartorelli L, Tognetti A, Giubilei F, Caregiver Study Group Savvy. The Savvy Caregiver Program: A Probe Multicenter Randomized Controlled Pilot Trial in Caregivers of Patients Affected by Alzheimer's Disease. J Alzheimers Dis 2016 Oct 04;54(3):1235-1246. [doi: 10.3233/JAD-160235] [Medline: 27567824]

15. Woods RT, Orrell M, Bruce E, Edwards RT, Hoare Z, Hounsome B, et al. REMCARE: Pragmatic Multi-Centre Randomised Trial of Reminiscence Groups for People with Dementia and their Family Carers: Effectiveness and Economic Analysis. PLoS One 2016 Apr 19;11(4):e0152843 [FREE Full text] [doi: 10.1371/journal.pone.0152843] [Medline: 27093052]

16. Bjørge H, Kvaal K, Ulstein I. The effect of psychosocial support on caregivers' perceived criticism and emotional over-involvement of persons with dementia: an assessor-blinded randomized controlled trial. BMC Health Serv Res 2019 Oct 24;19(1):744 [FREE Full text] [doi: 10.1186/s12913-019-4551-x] [Medline: 31651321]

17. Hamieh N, Sharara E, Salibi N, Mrad P, Chaaya M. Public Knowledge of, Perceptions About and Attitudes Towards Dementia: A Cross-Sectional Survey Among Lebanese Primary Health Care Attenders. Community Ment Health J 2019 Nov 3;55(8):1362-1368. [doi: 10.1007/s10597-019-00436-2] [Medline: 31270647]

18. Brodaty H, Thomson C, Thompson C, Fine M. Why caregivers of people with dementia and memory loss don't use services. Int J Geriatr Psychiatry 2005 Jun;20(6):537-546. [doi: 10.1002/gps.1322] [Medline: 15920707]

19. Novais T, Dauphinot V, Krolak-Salmon P, Mouchoux C. How to explore the needs of informal caregivers of individuals with cognitive impairment in Alzheimer's disease or related diseases? A systematic review of quantitative and qualitative studies. BMC Geriatr 2017 Apr 17;17(1):86 [FREE Full text] [doi: 10.1186/s12877-017-0481-9] [Medline: 28415968]

20. Lewis BA, Williams DM, Neighbors CJ, Jakicic JM, Marcus BH. Cost Analysis of Internet vs. Print Interventions for Physical Activity Promotion. Psychol Sport Exerc 2010 May 01;11(3):246-249 [FREE Full text] [doi:

10.1016/j.psychsport.2009.10.002] [Medline: 20401164] 
21. Hayden LJ, Glynn SM, Hahn TJ, Randall F, Randolph E. The use of Internet technology for psychoeducation and support with dementia caregivers. Psychol Serv 2012 May;9(2):215-218. [doi: 10.1037/a0027056] [Medline: 22662739]

22. Ploeg J, Markle-Reid M, Valaitis R, McAiney C, Duggleby W, Bartholomew A, et al. Web-Based Interventions to Improve Mental Health, General Caregiving Outcomes, and General Health for Informal Caregivers of Adults With Chronic Conditions Living in the Community: Rapid Evidence Review. J Med Internet Res 2017 Jul 28;19(7):e263 [FREE Full text] [doi: 10.2196/jmir.7564] [Medline: 28754652]

23. Sherifali D, Ali MU, Ploeg J, Markle-Reid M, Valaitis R, Bartholomew A, et al. Impact of Internet-Based Interventions on Caregiver Mental Health: Systematic Review and Meta-Analysis. J Med Internet Res 2018 Jul 03;20(7):e10668 [FREE Full text] [doi: 10.2196/10668] [Medline: 29970358 ]

24. Ploeg J, Ali MU, Markle-Reid M, Valaitis R, Bartholomew A, Fitzpatrick-Lewis D, et al. Caregiver-Focused, Web-Based Interventions: Systematic Review and Meta-Analysis (Part 2). J Med Internet Res 2018 Oct 26;20(10):e11247 [FREE Full text] [doi: 10.2196/11247] [Medline: 30368439]

25. Beauchamp N, Irvine AB, Seeley J, Johnson B. Worksite-based internet multimedia program for family caregivers of persons with dementia. Gerontologist 2005 Dec 01;45(6):793-801. [doi: 10.1093/geront/45.6.793] [Medline: 16326661]

26. Gustafson DH, Gustafson DH, Cody OJ, Chih M, Johnston DC, Asthana S. Pilot Test of a Computer-Based System to Help Family Caregivers of Dementia Patients. J Alzheimers Dis 2019;70(2):541-552. [doi: 10.3233/JAD-190052] [Medline: $\underline{31256126]}$

27. Núñez-Naveira L, Alonso-Búa B, de Labra C, Gregersen R, Maibom K, Mojs E, et al. UnderstAID, an ICT Platform to Help Informal Caregivers of People with Dementia: A Pilot Randomized Controlled Study. Biomed Res Int 2016;2016:5726465 [FREE Full text] [doi: 10.1155/2016/5726465] [Medline: 28116300]

28. Van Mierlo LD, Meiland FJ, Van de Ven PM, Van Hout HP, Dröes RM. Evaluation of DEM-DISC, customized e-advice on health and social support services for informal carers and case managers of people with dementia; a cluster randomized trial. Int Psychogeriatr 2015 Aug;27(8):1365-1378. [doi: 10.1017/S1041610215000423] [Medline: 25872457]

29. Cristancho-Lacroix V, Wrobel J, Cantegreil-Kallen I, Dub T, Rouquette A, Rigaud A. A web-based psychoeducational program for informal caregivers of patients with Alzheimer's disease: a pilot randomized controlled trial. J Med Internet Res 2015 May 12;17(5):e117 [FREE Full text] [doi: 10.2196/jmir.3717] [Medline: 25967983]

30. Meichsner F, Theurer C, Wilz G. Acceptance and treatment effects of an internet-delivered cognitive-behavioral intervention for family caregivers of people with dementia: A randomized-controlled trial. J Clin Psychol 2019 Apr;75(4):594-613. [doi: 10.1002/jclp.22739] [Medline: 30597537]

31. Kajiyama B, Thompson LW, Eto-Iwase T, Yamashita M, Di Mario J, Marian Tzuang Y, et al. Exploring the effectiveness of an internet-based program for reducing caregiver distress using the iCare Stress Management e-Training Program. Aging Ment Health 2013;17(5):544-554 [FREE Full text] [doi: 10.1080/13607863.2013.775641] [Medline: 23461355]

32. McKechnie V, Barker C, Stott J. Effectiveness of computer-mediated interventions for informal carers of people with dementia-a systematic review. Int Psychogeriatr 2014 Oct;26(10):1619-1637 [FREE Full text] [doi:

10.1017/S1041610214001045] [Medline: 24989249]

33. Zhao Y, Feng H, Hu M, Hu H, Li H, Ning H, et al. Web-Based Interventions to Improve Mental Health in Home Caregivers of People With Dementia: Meta-Analysis. J Med Internet Res 2019 May 06;21(5):e13415 [FREE Full text] [doi: 10.2196/13415] [Medline: $\underline{31066680}$ ]

34. Moher D, Liberati A, Tetzlaff J, Altman DG, PRISMA Group. Preferred reporting items for systematic reviews and meta-analyses: the PRISMA statement. BMJ 2009 Jul 21;339:b2535 [FREE Full text] [doi: 10.1136/bmj.b2535] [Medline: $\underline{19622551]}$

35. Deeks JH, Altman D. Assessing risk of bias in included studies. In: Cochrane Handbook for Systematic Reviews of Interventions. London: Cochrane Collaboration; 2008:211-242.

36. Higgins JPT, Thompson SG, Deeks JJ, Altman DG. Measuring inconsistency in meta-analyses. BMJ 2003 Sep 06;327(7414):557-560 [FREE Full text] [doi: 10.1136/bmj.327.7414.557] [Medline: 12958120]

37. Blom MM, Zarit SH, Groot Zwaaftink RBM, Cuijpers P, Pot AM. Effectiveness of an Internet intervention for family caregivers of people with dementia: results of a randomized controlled trial. PLoS One 2015 Feb 13;10(2):e0116622 [FREE Full text] [doi: 10.1371/journal.pone.0116622] [Medline: 25679228]

38. Brennan PF, Moore SM, Smyth KA. The effects of a special computer network on caregivers of persons with Alzheimer's disease. Nurs Res 1995;44(3):166-172. [Medline: 7761293]

39. Duggleby W, Ploeg J, McAiney C, Peacock S, Fisher K, Ghosh S, et al. Web-Based Intervention for Family Carers of Persons with Dementia and Multiple Chronic Conditions (My Tools 4 Care): Pragmatic Randomized Controlled Trial. J Med Internet Res 2018 Jun 29;20(6):e10484 [FREE Full text] [doi: 10.2196/10484] [Medline: 29959111]

40. Hattink B, Meiland F, van der Roest H, Kevern P, Abiuso F, Bengtsson J, et al. Web-Based STAR E-Learning Course Increases Empathy and Understanding in Dementia Caregivers: Results from a Randomized Controlled Trial in the Netherlands and the United Kingdom. J Med Internet Res 2015 Oct 30;17(10):e241 [FREE Full text] [doi: 10.2196/jmir.4025] [Medline: 26519106]

41. Hicken BL, Daniel C, Luptak M, Grant M, Kilian S, Rupper RW. Supporting Caregivers of Rural Veterans Electronically (SCORE). J Rural Health 2017 Jun;33(3):305-313. [doi: 10.1111/jrh.12195] [Medline: 27437642] 
42. Kales HC, Gitlin LN, Stanislawski B, Myra Kim H, Marx K, Turnwald M, et al. Effect of the WeCareAdvisor ${ }^{\mathrm{TM}}$ on family caregiver outcomes in dementia: a pilot randomized controlled trial. BMC Geriatr 2018 May 10;18(1):113 [FREE Full text] [doi: 10.1186/s12877-018-0801-8] [Medline: 29747583]

43. Metcalfe A, Jones B, Mayer J, Gage H, Oyebode J, Boucault S, et al. Online information and support for carers of people with young-onset dementia: A multi-site randomised controlled pilot study. Int J Geriatr Psychiatry 2019 Oct;34(10):1455-1464. [doi: 10.1002/gps.5154] [Medline: $\underline{31111516]}$

44. Possin KL, Merrilees JJ, Dulaney S, Bonasera SJ, Chiong W, Lee K, et al. Effect of Collaborative Dementia Care via Telephone and Internet on Quality of Life, Caregiver Well-being, and Health Care Use. JAMA Intern Med 2019 Dec 01;179(12):1658 (forthcoming). [doi: 10.1001/jamainternmed.2019.4101]

45. Torkamani M, McDonald L, Saez Aguayo I, Kanios C, Katsanou M, Madeley L, ALADDIN Collaborative Group. A randomized controlled pilot study to evaluate a technology platform for the assisted living of people with dementia and their carers. J Alzheimers Dis 2014;41(2):515-523. [doi: 10.3233/JAD-132156] [Medline: 24643137]

46. Williams K, Perkhounkova Y, Shaw C, Hein M, Vidoni E, Coleman C. Supporting Family Caregivers With Technology for Dementia Home Care: A Randomized Controlled Trial. Innov Aging 2019 Jul;3(3):igz037 [FREE Full text] [doi: 10.1093/geroni/igz037] [Medline: $\underline{31660443}$ ]

47. American Geriatrics Society Expert Panel on Person-Centered Care T. Person-Centered Care: A Definition and Essential Elements. J Am Geriatr Soc 2016 Jan 02;64(1):15-18. [doi: 10.1111/jgs.13866] [Medline: 26626262]

48. National Institute for Health and Care Excellence (UK). National Institute for Health and Care Excellence: Clinical Guidelines. Dementia: Assessment, Management and Support for People Living With Dementia and Their Carers. London: National Institute for Health and Care Excellence; 2018.

49. Fazio S, Pace D, Maslow K, Zimmerman S, Kallmyer B. Alzheimer's Association Dementia Care Practice Recommendations. Gerontologist 2018 Jan 18;58(suppl_1):S1-S9. [doi: 10.1093/geront/gnx182] [Medline: 29361074]

50. Australian and New Zealand Society for Geriatric Medicine. Position Statement 26 Management of Behavioural and Psychological Symptoms of Dementia (BPSD). Sydney, NSW: Australian and New Zealand Society for Geriatric Medicine; 2016.

51. Dauphinot V, Ravier A, Novais T, Delphin-Combe F, Mouchoux C, Krolak-Salmon P. Risk Factors of Caregiver Burden Evolution, for Patients With Subjective Cognitive Decline or Neurocognitive Disorders: A Longitudinal Analysis. J Am Med Dir Assoc 2016 Nov 01;17(11):1037-1043. [doi: 10.1016/j.jamda.2016.07.003] [Medline: 27575984]

52. Swinkels J, Broese van Groenou MI, de Boer A, Tilburg T. Male and Female Partner-Caregivers' Burden: Does It Get Worse Over Time? Gerontologist 2019 Nov 16;59(6):1103-1111. [doi: 10.1093/geront/gny132] [Medline: 30321338]

53. Morrin H, Fang T, Servant D, Aarsland D, Rajkumar AP. Systematic review of the efficacy of non-pharmacological interventions in people with Lewy body dementia. Int. Psychogeriatr 2017 Oct 09;30(3):395-407. [doi: $10.1017 / \mathrm{s} 1041610217002010]$

54. Caspar S, Davis ED, Douziech A, Scott DR. Nonpharmacological Management of Behavioral and Psychological Symptoms of Dementia: What Works, in What Circumstances, and Why? Innov Aging 2018 Jan;2(1):igy001 [FREE Full text] [doi: 10.1093/geroni/igy001] [Medline: $\underline{30480128]}$

55. Gilhooly KJ, Gilhooly MLM, Sullivan MP, McIntyre A, Wilson L, Harding E, et al. A meta-review of stress, coping and interventions in dementia and dementia caregiving. BMC Geriatr 2016 May 18;16:106 [FREE Full text] [doi: 10.1186/s12877-016-0280-8] [Medline: 27193287]

56. Schaller S, Marinova-Schmidt V, Gobin J, Criegee-Rieck M, Griebel L, Engel S, et al. Tailored e-Health services for the dementia care setting: a pilot study of 'eHealthMonitor'. BMC Med Inform Decis Mak 2015 Jul 28;15:58 [FREE Full text] [doi: 10.1186/s12911-015-0182-2] [Medline: 26215731]

\author{
Abbreviations \\ DEM-DISC: DEMentia Digital Interactive Social Chart \\ MD: mean difference \\ RCT: randomized controlled trials \\ SMD: Standardized mean differences
}


Edited by G Eysenbach; submitted 19.04.20; peer-reviewed by C Li, M Hu; comments to author 12.06.20; revised version received 25.06.20; accepted 26.07.20; published 09.09.20

Please cite as:

Leng $M$, Zhao Y, Xiao H, Li C, Wang Z

Internet-Based Supportive Interventions for Family Caregivers of People With Dementia: Systematic Review and Meta-Analysis

$J$ Med Internet Res 2020;22(9):e19468

URL: http://www.jmir.org/2020/9/e19468/

doi: $10.2196 / 19468$

PMID: 32902388

CMinmin Leng, Yajie Zhao, Hongmei Xiao, Ce Li, Zhiwen Wang. Originally published in the Journal of Medical Internet Research (http://www.jmir.org), 09.09.2020. This is an open-access article distributed under the terms of the Creative Commons Attribution License (https://creativecommons.org/licenses/by/4.0/), which permits unrestricted use, distribution, and reproduction in any medium, provided the original work, first published in the Journal of Medical Internet Research, is properly cited. The complete bibliographic information, a link to the original publication on http://www.jmir.org/, as well as this copyright and license information must be included. 